\title{
Research and Application of Work Roll Contour Technology on Thin Gauge Stainless Steel in Hot Rolling
}

\author{
Shao Jian ${ }^{*}, 1$, He Anrui ${ }^{1}$, Kong Fanfu ${ }^{1}$, Xiang Yang ${ }^{2}$ and Zhou Zhou ${ }^{3}$ \\ ${ }^{I}$ National Engineering Research Center of Advanced Rolling Technology, University of Science and Technology Beijing, \\ Beijing, 100083, China \\ ${ }^{2}$ Hot Strip Mill of Sichuan Southwest Stainless Steel Co., Ltd, Leshan, 614902, China \\ ${ }^{3}$ Hot Strip Mill of Beihai Chende Stainless Steel Co., Ltd, Beihai, 536000, China
}

\begin{abstract}
Shape control is the key technology for thin gauge stainless steel in hot rolling. Because of high rolling force, work roll can suffer from serious uneven wears, edge drop of strip temperature and so on. And in turn these imperfections lead to defects in thin gauge stainless steel production, such as big crown value, quarter wave, edge profile anomalies, poor rolling stability. In order to improve shape the control ability, one will have to eliminate the quarter wave, make roll wear uniform, increase rolling stability in the thin gauge stainless steel production, use high performance variable crown technology in upstream stands, use mixed variable crown technology in last stand, and use conventional work roll with variable shifting stroke strategy in other downstream stands. The above technologies have been successfully applied in several stainless steel productions, which have completely independent intellectual property rights, and the crown control precision of thin gauge stainless is $98.1 \%$, flatness control precision is $97.5 \%$, also a $1260 \mathrm{~mm} \times 1.6 \mathrm{~mm}$ ultra-thin gauge stainless steel was successfully developed.
\end{abstract}

Keywords: Hot rolling, stainless steel, shape control, work roll contour, quarter wave.

\section{INTRODUCTION}

Stainless steel is widely used in aerospace, petroleum, mechanical, chemical industry, biology and other fields because it is corrosion resistant, has high toughness and plasticity, and it is non-magnetic etc. The thin stainless steel raw material can give more flexible schedule for cold rolling, and can even take the place of cold rolling production, which is a developing trend for stainless steel rolling technology. Due to greater deformation resistance and poor hot ductility, big rolling force and fast temperature drops are a significant characteristic of the thin gauge stainless steel in hot rolling, this leads to serious shape problem and poor rolling stability, such as large crown value, anomalies at strip edge area and quarter wave.

Work roll contour is the most important factor of the shape control, and many outstanding shape control technologies are based on work roll contour design [1, 2]. In upstream stands of hot strip finishing mill, the main function is crown control, and flatness control is required in downstream stands [3]. Therefore, the work roll design targets are different between upstream and downstream stands according to different requirements. In order to improve the shape control capability, eliminate the quarter wave, make uniform work roll wear, and increase rolling stability in the thin gauge stainless steel production. The high performance variable crown work roll was developed and used in upstream stands, whereas the mixed variable crown work roll was developed and used in last stand, conventional work roll was used in the other stands with variable stroke shifting strategy technology.

\section{HIGH PERFORMANCE VARIABLE CROWN WORK ROLL}

Work roll bend is serious in stainless steel hot rolling because of high deformation resistance, and in order to get the profile target a good crown control capability is demanded. Variable crown work roll with axial shifting represented by three order curve can provide strong shape control capability [4-6]. As we all known, the shape control capability is inversely proportional to the strip width, which is similar to work roll bending, and poor capability can only be provided in narrow strip rolling with shifting in the limit position [7, 8]. Considering increasing shape control capability on various strip width, a new variable crown work roll was developed.

Variable crown work roll with axial shifting needs to satisfy the odd symmetrical conditions. Taking the midpoint of work roll as the origin coordinate and using polynomial expressions, the upper work roll radius curve function can be expressed as:

$$
y_{t}(x)=\sum_{i=1,3,5, \cdots}^{m} a_{i}\left(x-s_{0}\right)^{i}+\operatorname{sgn}\left(x-s_{0}\right) \sum_{j=2,4,6, \cdots}^{n} a_{j}\left(x-s_{0}\right)^{j}
$$


where $y_{t}(x)$ is the radius curve function of the upper work roll, $a_{i}$ is the roll curve coefficient, $s_{0}$ is the offset of roll curve, $x$ is abscissa of work roll, $\operatorname{sgn}\left(x-s_{0}\right)$ is the sign function shown as follow:

$$
\operatorname{sgn}\left(x-s_{0}\right)=\left\{\begin{array}{cc}
-1 & x-s_{0}<0 \\
0 & x-s_{0}=0 \\
1 & x-s_{0}>0
\end{array}\right.
$$

The upper work roll is symmetrical with $s_{0}$, and the lower work roll radius curve function can be expressed as:

$y_{b}(x)=\sum_{i=1,3,5, \cdots}^{m} a_{i}\left(x+s_{0}\right)^{i}-\operatorname{sgn}\left(x+s_{0}\right) \sum_{j=2,4,6, \cdots}^{n} a_{j}\left(x+s_{0}\right)^{j}$

where $y_{b}(x)$ is the radius curve function of lower work roll. Using the binomial theorem, the arbitrary odd $\left(x-s_{0}\right)^{i}$ and $\left(x+s_{0}\right)$ can be expressed as:

$$
\begin{aligned}
& \left(x-s_{0}\right)^{i}=\sum_{k=0}^{i} C_{i}^{k} x^{i-k}\left(-s_{0}\right)^{k} \\
& =x^{i}-C_{i}^{1} x^{i-1} s_{0}+C_{i}^{2} x^{i-2} s_{0}{ }^{2}-C_{i}^{3} x^{i-3} s_{0}{ }^{3}+\cdots-s_{0}{ }^{i} \\
& \left(x+s_{0}\right)^{i}=\sum_{k=0}^{i} C_{i}{ }^{k} x^{n-k} s_{0}{ }^{k} \\
& =x^{i}+C_{i}^{1} x^{i-1} s_{0}+C_{i}^{2} x^{i-2} s_{0}{ }^{2}+C_{i}^{3} x^{i-3} s_{0}{ }^{3}+\cdots+s_{0}{ }^{i}
\end{aligned}
$$

The roll gap function constructed by odd items can be expressed as:

$$
G_{i}(x)=2 a_{i} \sum_{k=1,3,5, \cdots}^{i} C_{i}^{k} x^{i-k} s_{0}{ }^{k}
$$

where $G_{i}(x)$ is the roll gap function, $C_{i}$ is coefficient of the binomial theorem expression. In the roll gap function constructed by odd items, the highest order term is $2 a_{i} C_{i}^{1} x^{i-}$ ${ }^{1} s_{0}$, and if neglecting the higher order terms, the roll gap function is $(i-1)$ order with the abscissa of work roll, therefore, the relationship between work roll equivalent crown and strip width is the same. Similarly, the work roll equivalent crown constructed by even items is $(i-1)$ order with strip width.

According to the roll gap forming principle, work roll contour can be composed of piecewise functions. As shown in Fig. (1), two order polynomial curve was used in the specified width interval $\left[L_{\mathrm{c}}, L_{q}\right]$, and three order polynomial curve was used in others.

The domains of piecewise function are as follows:

$$
\begin{aligned}
& X_{1}=\left[s_{0}-0.5 L_{c}, s_{0}+0.5 L_{c}\right] \\
& X_{2}=\left[s_{0}-0.5 L_{q}, s_{0}-0.5 L_{c}\right) \cup\left(s_{0}+0.5 L_{c}, s_{0}+0.5 L_{q}\right] \\
& X_{3}=\left[-0.5 L, s_{0}-0.5 L_{q}\right) \cup\left(s_{0}+0.5 L_{q}, 0.5 L\right]
\end{aligned}
$$

The piecewise function of work roll curve can be shown as follow:

$$
y_{t}(x)= \begin{cases}y_{1}(x)=a_{1}\left(x-s_{0}\right)+a_{2}\left(x-s_{0}\right)^{3} & x \in X_{1} \\ y_{2}(x)=a_{3}\left(x-s_{0}\right)+a_{4} \operatorname{sgn}\left(x-s_{0}\right)\left(x-s_{0}\right)^{2} & x \in X_{2} \\ y_{3}(x)=a_{5}\left(x-s_{0}\right)+a_{6}\left(x-s_{0}\right)^{3} & x \in X_{3}\end{cases}
$$

The work roll equivalent crown adjusting ability is expressed as:

$$
C_{r}(s, w)= \begin{cases}\frac{3}{2} a_{2}\left(s_{0}+s\right) w^{2} & , w<L_{c} \\ \left(s_{0}+s\right)\left[\frac{3}{2} a_{2} L_{c}^{2}+2 a_{4}\left(w-L_{c}\right)\right] & , L_{c} \leq w \leq L_{q} \\ \left(s_{0}+s\right)\left[\frac{3}{2} a_{2} L_{c}{ }^{2}+2 a_{4}\left(L_{q}-L_{c}\right)+\frac{3}{2} a_{6}\left(w^{2}-L_{q}{ }^{2}\right)\right], w>L_{q}\end{cases}
$$

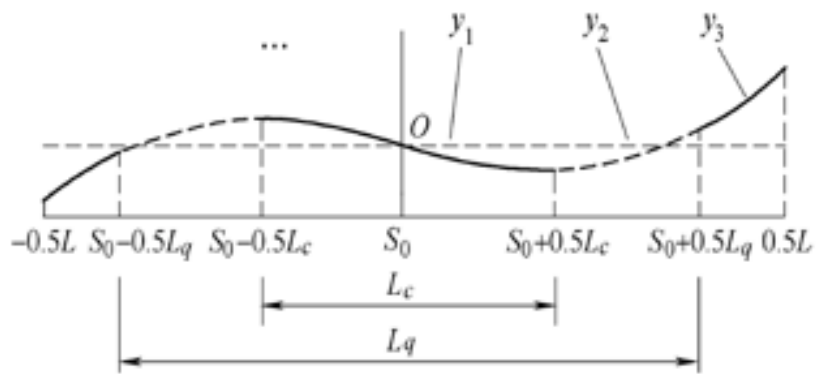

Fig. (1). Piecewise function of work roll contour.

In equation (9), the relationship between equivalent crown adjusting ability and strip width is linear in $\left[L_{c}, L_{\mathrm{q}}\right]$, while in other width range, the relationship is square. According to the crown adjusting ability characteristic, a high performance variable crown (HVC) was developed. As shown in equation (8), there are seven parameters, $s_{0}, a_{1}, a_{2}$, $a_{3}, a_{4}, a_{5}, a_{6}$, and so seven equations are required in roll contour design.

In roll contour design, there are some known conditions, such as work roll length $(L)$, shifting limit position $\left(s_{\mathrm{m}}\right)$, linear width range $\left(L_{c}\right.$ and $\left.L_{q}\right)$, work roll equivalent crown based on shifting limit position $\left(C_{r 1}\right.$ and $\left.C_{r 2}\right)$. According to equation (9), $C_{r 1}$ and $C_{r 2}$ are given as follows:

$$
\left\{\begin{array}{l}
C_{r 1}=C_{r}\left(-s_{m}, L\right) \\
C_{r 2}=C_{r}\left(s_{m}, L\right)
\end{array}\right.
$$

Based on continuity requirements of HVC work roll piecewise function, the following equations can be achieved:

$$
\begin{aligned}
& \left\{\begin{array}{l}
y_{1}\left(s_{0}+0.5 L_{c}\right)=y_{2}\left(s_{0}+0.5 L_{c}\right) \\
y_{1}^{\prime}\left(s_{0}+0.5 L_{c}\right)=y_{2}^{\prime}\left(s_{0}+0.5 L_{c}\right)
\end{array}\right. \\
& \left\{\begin{array}{l}
y_{2}\left(s_{0}+0.5 L_{q}\right)=y_{3}\left(s_{0}+0.5 L_{q}\right) \\
y_{2}^{\prime}\left(s_{0}+0.5 L_{q}\right)=y_{3}^{\prime}\left(s_{0}+0.5 L_{q}\right)
\end{array}\right.
\end{aligned}
$$


The minimum deviation diameter or axial force of work roll is a design objective, and it can establish an equation with the same roll deviation diameter under the main rolling width $w_{m}$ :

$y\left(0.5 w_{m}\right)=y\left(-0.5 w_{m}\right)$

From the seven nonlinear equations (10-13), seven roll parameters can be solved, and the HVC work roll contour can also be established. Considering the work roll length as $(L=2550$ $\mathrm{mm})$, shifting limit position as $\left(s_{\mathrm{m}}=150 \mathrm{~mm}\right)$, linear width range as $\left(L_{c}=1200 \mathrm{~mm}, L_{q}=2000 \mathrm{~mm}\right)$, and equivalent crown as $\left(C_{r 1}=-\right.$ $0.9 \mathrm{~mm}, C_{r 2}=0.5 \mathrm{~mm}$ ), the three order work roll and HVC were designed and the crown adjusting ability was compared under various strip width, as shown in Fig. (2).

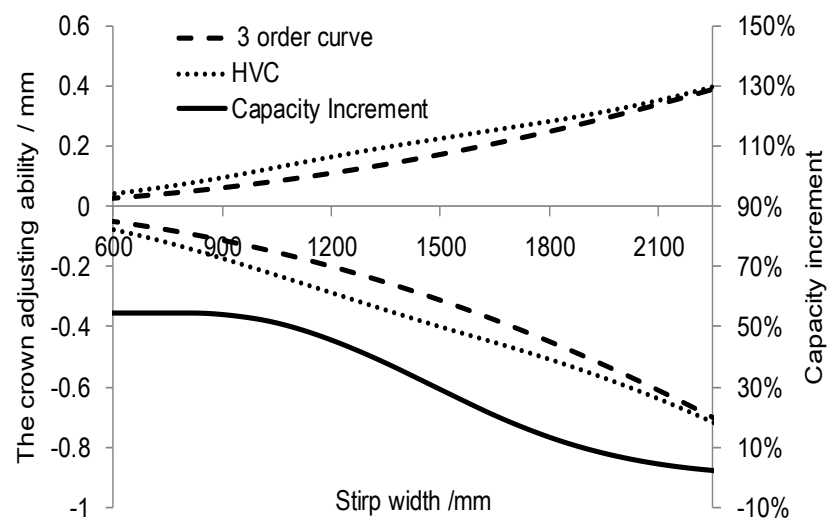

Fig. (2). Crown adjusting ability comparison between HVC and 3 order curve.

As shown in Fig. (2), along with the drop of strip width, HVC work roll equivalent crown adjusting ability decreases slowly than third order curve work roll because of the linear relationship between equivalent crown and width. HVC contour adopt piecewise function, makes the equivalent crown not only linearly proportional to shift position, but also to strip width in specified range, therefore, enhances overall shape control capacity of mills. HVC contour has a stronger crown adjustment capacity than 3 order curve work roll, especially for the narrow strip.

\section{MIDDLE VARIABLE CROWN WORK ROLL}

Quarter wave is the main high order shape defect in thin gauge stainless steel rolling, as shown in Fig. (3). The reasons for high order shape defect are mainly as follows: 1 ) strip factors, such as transverse uneven temperature, transverse uneven alloy components, profile anomalies and so on. 2) Roll factors, such as roll transverse serious uneven wear, roll transverse uneven temperature distribution, roll grinding precision and so on. 3) Roll deformation factors, such as high order bending of work roll and backup roll under high rolling forces. Some of the above factors can be avoided or lessened in the production process, such as the profile anomalies, roll grinding precision, uneven alloy components and so on, but the others cannot be solved due to equipment problems. Therefore, work roll compensation technology has been considered to eliminate the quarter wave.

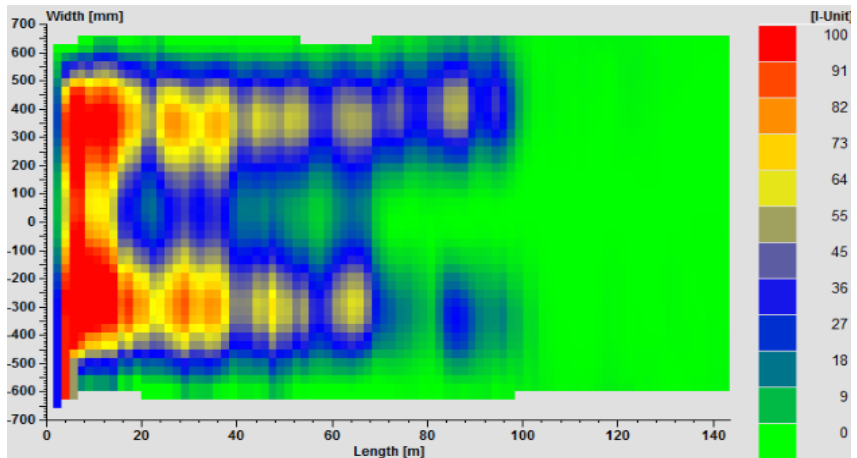

Fig. (3). Quarter wave in thin gauge stainless steel rolling.

In the roll length range, parabolic flatness was considered to design work roll conventional curve. If center buckle is the main shape defect of stainless steel, designing parabolic curve for work roll, making work roll intermediate diameter small and both ends of the roll diameter larger. If edge wave is familiar, then the adjustment will be opposite. Parabolic curve equation of the work roll is as follows:

$y(x)=k_{2} x^{2} \quad-0.5 L \leq x \leq 0.5 L$

where $L$ is work roll length, $x$ is work roll abscissa with the midpoint of origin, $y(x)$ is parabolic work roll radius curve, $k_{2}$ is parabolic curve parameter.

If asymmetric flatness appears in different position on either side of strip center line, or different flatness appears in the same position, then two sixth order curves are designed on the basis of wave defect location and size on both sides of strip, as shown in Fig. (4).

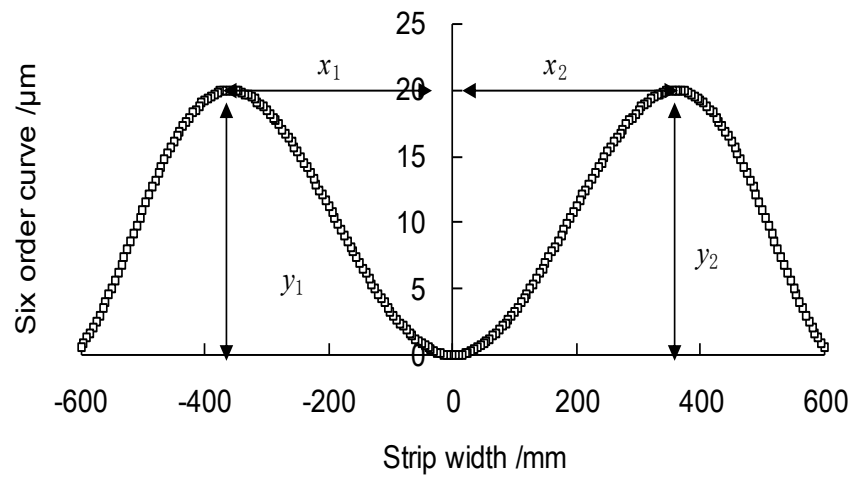

Fig. (4). Six order curve for compensation.

In the range of $[-0.5 w, 0]$ and $(0,0.5 w]$, parabolic curve by superimposing two six order curves, middle variable crown (MVC) work roll is obtained, as shown in Fig. (5), and the formula is as follow:

$$
y(x)=\left\{\begin{array}{lc}
k_{2} x^{2}+\left(b_{2} x^{2}+b_{4} x^{4}+b_{6} x^{6}\right) & -0.5 w \leq x \leq 0 \\
k_{2} x^{2}+\left(c_{2} x^{2}+c_{4} x^{4}+c_{6} x^{6}\right) & 0<x \leq 0.5 w \\
k_{2} x^{2} & -0.5 L \leq x<-0.5 w, \\
& 0.5 w<x \leq 0.5 L
\end{array}\right.
$$

where $L$ is the work roll length, $w$ is the strip width, $y(x)$ is the MVC radius curve, $b_{2}, b_{4}, b_{6}, c_{2}, c_{4}$, and $c_{6}$ are the parameters of the six order curve which satisfy the following equations: 


$$
\begin{aligned}
& \left\{\begin{array}{l}
b_{2} x_{1}{ }^{2}+b_{4} x_{1}{ }^{6}+b_{6} x_{1}{ }^{6}=y_{1} \\
2 b_{2}+4 b_{4} x_{1}{ }^{2}+6 b_{6} x_{1}{ }^{4}=0 \\
b_{2}(0.5 w)^{2}+b_{4}(0.5 w)^{4}+b_{6}(0.5 w)^{6}=0
\end{array}\right. \\
& \left\{\begin{array}{l}
c_{2} x_{2}{ }^{2}+c_{4} x_{2}{ }^{6}+c_{6} x_{2}{ }^{6}=y_{2} \\
2 c_{2}+4 c_{4} x_{2}{ }^{2}+6 c_{6} x_{2}{ }^{4}=0 \\
c_{2}(0.5 w)^{2}+c_{4}(0.5 w)^{4}+c_{6}(0.5 w)^{6}=0
\end{array}\right.
\end{aligned}
$$

where, $x_{1}, x_{2}$ are the distance from the strip center of asymmetry high order wave, $y_{1}, y_{2}$ are the maximum values for the sixth order radius curve, which is used to compensate for the asymmetry high order wave, usually, the values of $y_{1}$, $y_{2}$ are between $20 \mu \mathrm{m}$ and $50 \mu \mathrm{m}$, the quarter wave is larger, and the $y_{1}$ and $y_{2}$ are bigger.

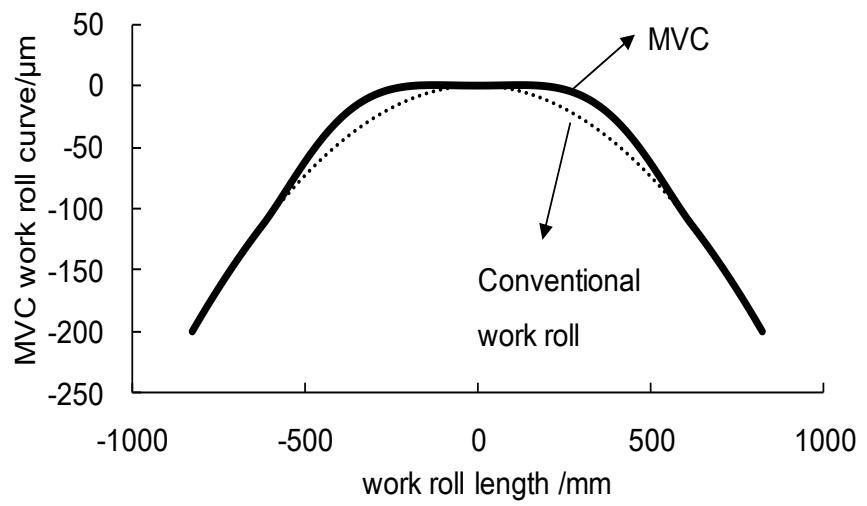

Fig. (5). MVC work roll curve for stainless steel rolling.

As shown in Fig. (6), after using MVC work roll technology in the last stand of hot rolling, a good shape was achieved, and quarter wave was eliminated by work roll compensation technology.

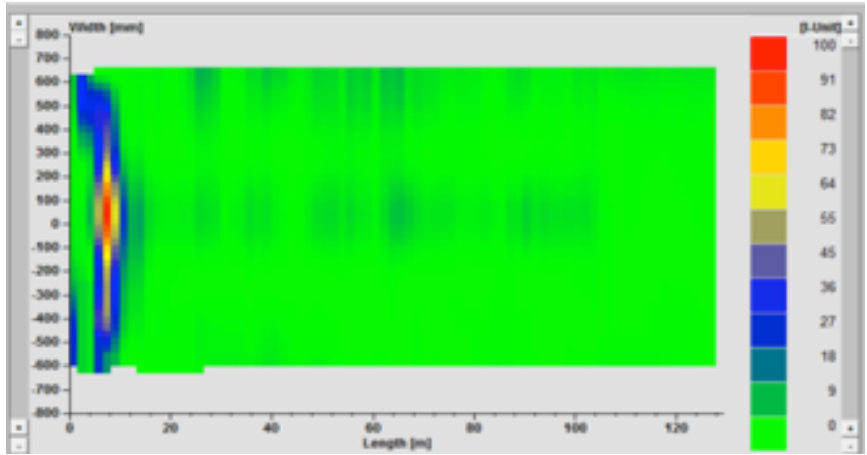

Fig. (6). Good shape quality in thin gauge stainless steel rolling after using MVC.

\section{VARYING SHIFTING STROKE STRATEGY OF CONVENTIONAL WORK ROLL}

According to different contour curves, work roll shifting technology in hot strip mills can be divided into a conventional work roll shifting strategy (such as sine curve, parabolic curve, etc.) and high order work roll shifting strategy (such as CVC, Smart Crown, etc.) [9, 10]. Work roll wear in stainless steel rolling is 1.5-2.0 times than the plain carbon steel because of its high rolling force [11], transverse serious uneven temperature, and in the later stages of rolling campaign, the profile anomalies becomes more and more obvious. Conventional work roll with shifting along the axial direction can uniform a work roll wear and get a good profile $[12,13]$. Shifting strategy for conventional work rolls includes three parameters: shifting step $t_{\mathrm{s}}$, shifting stroke $k_{\mathrm{s}}$ and shifting frequency $f_{\mathrm{s}}$, which respectively refers to the magnitude of shifting, the maximum value of shifting, towards the operation side or driving side and the calculation frequency of shifting setup.

At the beginning of the rolling campaign, the amount of work roll wear is small, then as the shifting stroke is operated at a maximum value, wear width $B_{w}$ is made larger, wear anomalies height $H_{c}$ grows smaller and the edge wear of the work roll is uniform. With an increase of work roll wear, shifting stroke changes to minimize influence the loading gap profile and quarter wave caused by shifting. Varying shifting stroke strategy algorithm is as follows:

1) If $L_{i} \leq L_{\mathrm{s}}$

where $L_{i}$ is the rolling kilometers of last stand in finishing mill, $L_{s}$ is rolling kilometers when the shifting stroke begins to change. When, $L_{i} \leq L_{\mathrm{s}}$, the work roll shifting $S_{i}$ can be calculated by the same parameters as shifting strategy and is expressed as follows:

$$
S_{i}=\left\{\begin{array}{lc}
0 & i \leq N \\
S_{i-1} & i>N \text { and } i \% f_{s} \neq 0 \\
S_{i-1}+D_{r} \times t_{s} & i>N \text { and } i \% f_{s}=0
\end{array}\right.
$$

where, $N$ is the strip number for beginning shifting and values range from 1 to 3 generally. $D_{r}$ is the shifting beginning direction and initial values are \pm 1 generally. The comparion between shifting $S_{i}$ and shifting stroke $k_{\mathrm{s}}$ requires the following relationship:

$S_{i}=\left\{\begin{array}{rr}k_{s}, D_{r}=-D_{r} & S_{i}>k_{s} \\ -k_{s}, D_{r}=-D_{r} & S_{i}<-k_{s}\end{array}\right.$

2) If $L_{i}>L_{\mathrm{s}}$

when $L_{i}>L_{\mathrm{s}}$, calculate the permissible shifting stroke $k_{i}$ of the $i$ strip.

$$
\begin{aligned}
& \Delta k_{\mathrm{s}}=k_{\mathrm{s} 1}-k_{\mathrm{s} 2} \\
& k=\frac{\Delta k_{s}}{L_{m}} \\
& k_{i}=k_{s 1}-k \times\left(L_{i}-L_{\mathrm{s}}\right)
\end{aligned}
$$

where, $k_{\mathrm{s} 1}$ is initial shifting stroke, $k_{\mathrm{s} 2}$ is shifting stroke in the end of rolling, $\Delta k_{\mathrm{s}}$ is the difference between $k_{\mathrm{s} 1}$ and $k_{\mathrm{s} 2}, k$ is the variation coefficient of shifting stroke, $L_{\mathrm{m}}$ is rolling kilometers when the shifting stroke change to $k_{\mathrm{s} 2}$. After establishing the value of $k_{i}$, we can get $S_{i}$ by using formula (18) and Si meets the demands below:

$S_{i}=\left\{\begin{aligned} k_{i}, D_{r}=-D_{r} & S_{i}>k_{i} \\ -k_{i}, D_{r}=-D_{r} & S_{i}<-k_{i}\end{aligned}\right.$

varying shifting stroke strategy has been used in the finishing mills of hot strip mills. Operator can choose the shifting mode on the human machine interface (HMI). By configuring the shifting step $t_{\mathrm{s}}$, shifting stroke $k_{\mathrm{s}}$ and the 
shifting frequency $f_{\mathrm{s}}$, good profile and rolling stability were achieved. Varying shifting stroke strategy in a rolling unit is shown in Fig. (7).

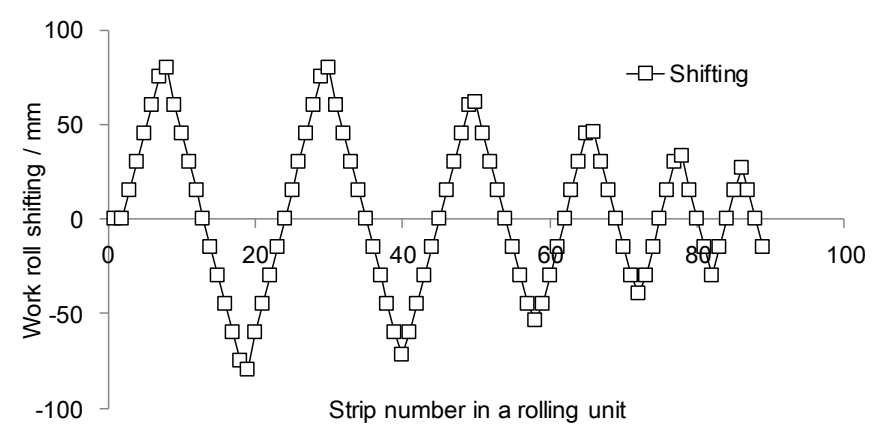

Fig. (7). Varying shifting stroke strategy in a rolling unit.

\section{INDUSTRIAL APPLICATION}

$1450 \mathrm{~mm}$ hot strip mill of Sichuan southwest stainless steel, $1630 \mathrm{~mm}$ hot strip mill of Beihai Chengde southwest stainless steel, $1780 \mathrm{~mm}$ hot strip mill of Dingxin southwest stainless steel were put into operation in 2008, 2012 and 2014 respectively. In $1450 \mathrm{~mm}$ hot strip mill, the quarter wave was serious and rolling stability was poor because of its high rolling force, the edge temperature drop and so on, by using HVC, MVC, and varying shifting stroke strategy of conventional work roll, the problem has been resolved effectively, and this technology has also been applied in the other two stainless steels.

For example, $1630 \mathrm{~mm}$ hot rolling mill is a modern wide stainless steel production line which has been independently integrated domestically. It's main equipment's include: Two walking beam furnaces, one rough descaling device with high pressure water, one four high reversible rough rolling mill with vertical rolls, one coilbox with double-working position, one flying shear, 8 stands four high finishing mills, two down coilers, one coil conveyer, binding machine and weighing machine. The designed annual production capacity is 1.6 million ton, including 200 and 300 series austenitic stainless steel, 400 series ferrite and martensitic stainless steel, and the scope of product specification is $1.6 \sim 8.0$ $\mathrm{mm} \times 830 \sim 1520 \mathrm{~mm}$. In order to improve its shape control ability, eliminate quarter wave, make uniform work roll wear, and increase rolling stability in thin gauge stainless steel production, HVC technology is used in upstream stands, MVC is used in last stand, and conventional work roll $(\mathrm{CON})$ with variable shifting stroke strategy is used in other downstream stands, as shown in Fig. (8).

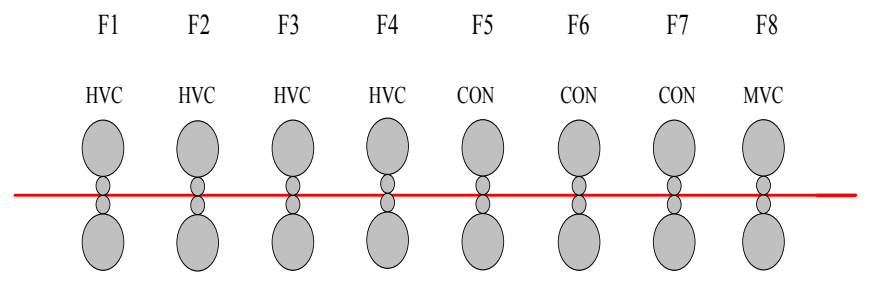

Fig. (8). Work roll technology using in $1630 \mathrm{~mm}$ hot strip mill for stainless steel rolling.

Using work roll technology, the production process stability is improved and the product quality achieved good results. As shown in Fig. (9), the number of stainless steel is 449 , and more than $49.67 \%$ steel thickness is less than 2.2 $\mathrm{mm} .1240 \mathrm{~mm} \times 1.6 \mathrm{~mm}$ ultra-thin gauge stainless steel in hot rolling is also developed.

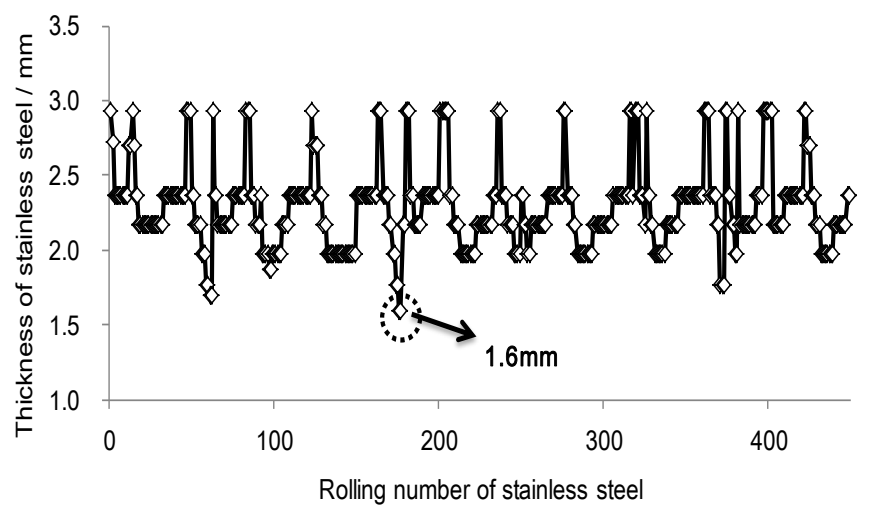

Fig. (9). Thickness of stainless steel rolling.

The crown hit rate of stainless steel reaches $98.1 \%$ in absolute error range of $\pm 15 \mu \mathrm{m}$, and the flatness hit rate reaches $97.5 \%$ in absolute error range of $\pm 25 \mathrm{IU}$, at the same time, quarter wave had been eliminated after using MVC work roll technology.

\section{CONCLUSION}

Due to high rolling force, serious edge temperature drop, high order roll bending and so on, quarter wave, bad profile and poor rolling stability are common problems in stainless steel rolling. Under the premise of limited conditions, as mentioned above, the work roll technology is the key to solving these problems. HVC enhances the shape control capacity of the mills, especially for the narrow strip. MVC eliminates the quarter wave by superimposing the sixth order curve, and conventional work roll with shifting along the axial direction can make the work roll wear uniform and obtain a good profile. The application on hot strip mills for stainless steel rolling indicates that work roll technologies achieved the desired results in both shape control and rolling stability.

\section{CONFLICT OF INTEREST}

The authors confirm that this article content has no conflict of interest.

\section{ACKNOWLEDGEMENTS}

This work was supported by Beijing Higher Education Young Elite Teacher Project (YETP0413) and Technology Development Plan of Guangxi Province (2013AA01001).

\section{REFERENCES}

[1] A. Seilinger, A. Mayrhofer, and A. Kainz, "SmartCroum - A new system for improved profile and flatness control", Aluminium International Today, vol. 15, pp. 26-28, March 2003.

[2] W. Bald, G. Beisemann, H. Feldmann, and T. "Continuously variable crown (CVC) rolling", Iron and Steel Engineering, vol.22, pp.32-40, March 1987. 
[3] J. G. Cao, J. Zhang, X. L. Chen, G. C. Wei, P. Song, and Y. Su, "Selection of strip mill configuration and shape control", Iron and Steel, vol.40, pp.40-43, June 2005.

[4] H. B. Li, J. Zhang, J. G. Cao, Z. M. Wang, Q. Wang, and S. S. Zhang, "Analysis and selection of crown control ranges for CVC work rolls in CSP hot rolling", J. University of Science and Technology Beijing, vol. 32, pp.118-122, January 2010.

[5] J. Zhang, X. L. Chen, Y. H. Xu, and Y. Zhang, "Roll contour design of 4-high mill with variable crown by axial shifting", $J$. University of Science and Technology Beijing, vol.16, pp.98-101, November 1994.

[6] H. B. Li, J. Zhang, J. G. Cao, X. M. Si, and S. X. Zhang, "Control characteristics contrast among cubic CVC, quintic CVC and SmartCrown roll controus", China Mechanical Engineering, vol.20, pp.237-240, January 2009.

[7] A. R. He, Q. Yang, X. L. Chen, L. Zhao, H. R. Dong, and Y. Q. $\mathrm{Xu}$, "Development and application of linearly variable crown work roll in hot strip mills", Chinese Journal of Mechanical Engineering, vol.44, pp.255-259, November 2008.
[8] R. Z. Wang, A. R. He, Q. Yang, L. Zhao, and H. R. Dong, "Profile control capability of LVC work roll contour", Iron and Steel, vol.41, pp.41-44, May 2006

[9] G. C. Wei, J. G. Cao, J. Zhang, J. W. Hao, and G. Chen, "Optimization and application of CVC work roll contour on 2250 hot strip mills", Journal of Central South University (Science and Technology), vol.38, pp.937-942, October 2007.

[10] J. Shao, A. R. He, Q. Yang, and N. A. Shi, "Simulation and application of shape setup control system in hot strip mill", Journal of Iron and Steel Research, vol.20, pp.53-56, June 2008.

[11] J. Shao, A. R. He, Q. Yang, and H. W. Guo, "Research on work roll wear prediction model taking in account lubrication in hot rolling”, China Mechanical Engineering, vol.20, pp. 361-364, February 2009.

[12] X. W. Kong, J. Z. Xu, D. Y. Gong, and G. D. Wang, "Optimum shift scheme of SFR realized by adopting flat roll", J. Northeastern University, vol. 23, pp. 20-22, December 2002.

[13] Q. D. Zhang, A. R. He, L. W. Huang, X. L. Chen, G. C. Wei, and S. Q. Huang, "shape control in schedule free hot strip rolling", Iron and Steel, vol.36, pp.72-75, February 2001.

This is an open access article licensed under the terms of the Creative Commons Attribution Non-Commercial License (http://creativecommons.org/licenses/by-nc/3.0/) which permits unrestricted, non-commercial use, distribution and reproduction in any medium, provided the work is properly cited. 